\title{
The ASEAN experience of the purchasing power parity theory
}

\author{
S. M. Woahid Murad ${ }^{1 *}$ (D) and Mohammad Amzad Hossain ${ }^{2}$
}

\author{
* Correspondence: \\ w.murad@nstu.edu.bd \\ 'Department of Economics, \\ Noakhali Science and Technology \\ University, Noakhali 3814, \\ Bangladesh \\ Full list of author information is \\ available at the end of the article
}

\begin{abstract}
We used panel data analysis to evaluate the relative purchasing power parity (PPP) hypothesis of the ten ASEAN member countries between 1973 and 2015. We incorporated the cross-sectionally augmented panel unit root test as proposed by Pesaran (J Appl Econ 22:265-312, 2007). For panel cointegration analysis, we employed the four error-correction-based Westerlund (Oxf Bull Econ Stat 69:709748,2007 ) panel cointegration tests. The Westerlund (Oxf Bull Econ Stat 69:709$748,2007)$ tests are general enough to permit a large degree of heterogeneity, both in the long-run cointegrating relationship and in the short-run dynamics, and dependence within as well as across the cross-sectional units. To check the robustness of the results, we further estimated the cointegration test excluding Indonesia and Brunei. The findings support our initial results. Further, all the results overwhelmingly support the relative PPP hypothesis. Consequently, the monetary authority would be able to implement a self-regulating monetary policy. It would also be able to control the exchange rates.
\end{abstract}

Keywords: Purchasing power parity, Panel unit root test, Panel cointegration test, ASEAN countries

JEL classifications: F31, F37, C32, C33

\section{Introduction}

The inspection of Purchasing Power Parity (PPP) has been one of the most controversial topics in the last few decades in international economics (Rogoff 1996 and Taylor and Taylor 2004). PPP theory is used to balance the comparative value of currencies by estimating the adjustment and required for the exchange rate to correspond to countries' purchasing power.

The literature examining this hypothesis is extensive. Froot and Rogoff (1995), Taylor and Sarno (1998), O'Connell (1998), Anker (1999), and Breitung and Candelon (2005) have presented the theoretical background and empirical evidence of the PPP-real exchange rates relationship. Froot and Rogoff (1995) found that the real exchange rate is stationary over sufficiently long horizons. According to Froot and Rogoff (1995), the Balassa-Samuelson hypothesis can be considered as an alternative model. Taylor and Sarno (1998), found that the real exchange rates among the G5 are CPI-adjusted, which means that the exchange rates are apparently mean reverting over the floating rate period. O'Connell (1998) and Anker (1999) emphasized controlling the

(c) The Author(s). 2018 Open Access This article is distributed under the terms of the Creative Commons Attribution 4.0 International License (http://creativecommons.org/licenses/by/4.0/), which permits unrestricted use, distribution, and reproduction in any medium, provided you give appropriate credit to the original author(s) and the source, provide a link to the Creative Commons license, and indicate if changes were made. 
cross-sectional dependence in case of investigating the random walk effect of the panel data of real exchange rates. Breitung and Candelon (2005) considered structural breaks and found that the PPP hypothesis holds in the Asian countries, which experienced a flexible exchange rate; on the contrary, the South and Latin American currencies, which are in the pegged regime for a long time, do not hold the PPP hypothesis.

The panel unit root test has been used extensively in recent times to observe the unit root of real exchange rates. For instance, Fleissig and Strauss (2000), Engel (2000), Wu and Wu (2001), and Sarno and Taylor (2002) found that real exchange rates follow a stationary process. Murad (2016) used first-generation and second-generation panel unit root tests and found that the exchange rate of the Bangladeshi taka is mean-reverting. Banerjee (1999), Baltagi and Kao (2000), and Pedroni (2000, 2001) advocated the panel cointegration framework to draw econometrically rigorous conclusions.

Very few papers have explored PPP in the context of data on Asian exchange rates thus far. Kim et al. 2009 expressed concerns over the PPP assumption in Southeast Asian countries. Investigations of the nonlinear PPP relationship using Southeast Asian data were conducted by Aggarwal et al. (2000), Zurbruegg and Allsopp (2004), and Wu et al. (2004). Their findings show that the unit root null rejection speed is larger in the case of a structural break investigation. Aggarwal et al. (2000) found that the relationship between exchange rate and price levels of two nations were stronger when the Japanese yen was considered as a numeraire compared to other reference currencies. Zurbruegg and Allsopp (2004) found that the exchange rates of Hong Kong, Singapore, Philippines, South Korea, Japan, and Malaysia, converged to the long-run PPP. They advocated that the PPP hypothesis may be investigated further in the contexts of Indonesia and Thailand. Wu et al. (2004) used monthly data and found that real exchange rates among Pacific Basin countries are mean reverting. Unlike the results obtained from the monthly data, the authors obtained mixed results while considering quarterly data. They rejected the unit-root hypothesis that real exchange rates are nonstationary only in Thailand, the Philippines, and South Korea out of eight countries, namely, Taiwan, Thailand, the Philippines, Malaysia, Indonesia, Singapore, Japan, and South Korea, based on the Zivot-Andrews statistic.

Applying the unit root test developed by Kapetanios et al. (2003) for a nonlinear Exponential Smooth Transition Auto-Regression (ESTAR) stationary alternative to 11 Asian real exchange rates, Liew et al. (2004) found the PPP relationship. When the US dollar was the numeraire currency, they found that two-thirds of the real exchange rates of Southeast Asian currencies were consistent with nonlinear stationary processes. On the contrary, when Japanese yen was considered as a numeraire currency, $60 \%$ of the real exchange rates are mean reverting. According to their findings, price levels in Asian countries adjust more quickly to the US price level than the Japanese price level.

Choudhry (2005) found that the Generalized Purchasing Power Parity (G-PPP) held in the ASEAN 4 countries (Thailand, Malaysia, Indonesia, and the Philippines). On the other hand, Ogawa and Kawasaki (2006) found the facts of the G-PPP relationship in the case of the ASEAN 5 countries (Indonesia, Malaysia, the Philippines, Singapore, and Thailand), as well as China and Korea. Ahn et al. (2006) also identified the continuation of the G-PPP in Singapore, Indonesia, Malaysia, and Thailand, as well as the four Northeast Asian Economies of Taiwan, Korea, Hong Kong, and Japan. Chang et al. 
(2012) applied a simple and powerful nonlinear unit root test and found that PPP only holds for Indonesia, Malaysia, and Thailand out of eight ASEAN countries, namely, Cambodia, Indonesia, Laos, Malaysia, the Philippines, Singapore, Thailand, and Vietnam and the adjustment toward PPP was nonlinear and asymmetric. Ma et al. (2017) developed some empirical tests for the PPP hypothesis in East Asian countries by incorporating the quintile unit root and quintile cointegrating regression method. They found that the PPP hypothesis holds in China, Japan, and South Korea. Chen and $\mathrm{Hu}$ (2018) considered a sample of 178 countries covering the period from 2000 to 2013 and found that the consumer price index (CPI) and PPP are positively correlated. They also found that the PPP has an exchange rate pass-through effect on the price level. $\mathrm{Ha}$ (2018) examined the validity of the PPP hypothesis by analyzing panel data of nine countries in Southeast Asia, namely Vietnam, Laos, Cambodia, Thailand, Myanmar, Malaysia, Singapore, Indonesia, and the Philippines between January 1995 and February 2017, in terms of the US Dollar and Japanese Yen. The absolute PPP was rejected by the panel unit root test for Southeast Asian countries. However, when Ha (2018) incorporated the panel unit root test considering structural breaks in the data, he found that the PPP theory seemed to hold over the period from July 1997 to August 2008, that is, after the Asian financial crisis ended in 1997 and before the global financial crisis began in 2008 .

Most prior studies on the PPP theory concentrated on ASEAN economies employed time series econometric techniques. The drawback of such techniques is that they have limited power against the alternative hypothesis, with a highly persistent deviation from equilibrium. Thus, there is the possibility that it may mislead policy initiatives. Although some papers have incorporated first-generation panel data approaches, such techniques do not work well in the presence of cross-sectional dependence. Many prior studies, for instances, Baharumshah and Ariff (1997), Wu and Chen (1999), have failed to reject the null hypothesis of no-cointegration even in cases where cointegration was strongly suggested by theory. The reason is that most residual-based cointegration tests, both in pure time-series and in panels, require the long-run parameters for the variables in their levels to be equal to the short-run parameters for the variables in their differences. This failure can cause a significant loss of power for residual-based cointegration tests. On the contrary, Westerlund (2007) developed four new panel cointegration tests based on structural, rather than residual, dynamics. Therefore, these tests do not impose any common-factor restriction.

We did not find any study on PPP theory in the context of the ASEAN member countries that relied on such second-generation panel cointegration tests. Therefore, this paper attempts to investigate the validity of the PPP theory in the context of ASEAN economies using second-generation panel data approaches. Since the PPP theory does not work well in a short span of time, we consider all the member countries of the ASEAN in this paper (Brunei Darussalam, Cambodia, Indonesia, Lao PDR, Malaysia, Myanmar, the Philippines, Singapore, Thailand, and Vietnam) and use annual data from 1973 to 2015. The data were obtained from the World Development Indicators (WDI) published by the World Bank and the International Financial Statistics (IFS) CD-ROM published by the International Monetary Fund.

In the next section, we develop and present a model of the PPP theory. The third section presents the sources of data and the methodologies used in this study. The 
empirical results are presented in the subsequent section and finally, the fifth section offers concluding remarks.

\section{Theoretical framework}

The following regression model is frequently considered in examining the relative PPP hypothesis ${ }^{1}$ :

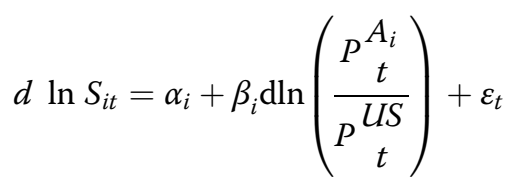

where, $S_{i, t}$ is the bilateral nominal exchange rate of the currency of the $i^{\text {th }}$ ASEAN member country against the US dollar and $P t^{\mathrm{Ai}}$ and $P t^{U S}$ are the aggregate price levels of the $i^{\text {th }}$ ASEAN member country and the US respectively. Here, a one period change in the variable is denoted by $d$ and the natural $\log$ transformation is denoted by $\ln$. According to the PPP theory, it is expected that $\alpha_{i}=0$ and while $\beta_{i}=1$. Hence, the relative change in the exchange rate would be equal to the relative change in the ratio of price levels of two economies.

\section{Data and methodology}

Data source

We obtained annual data of the nominal exchange rates of the selected countries' currencies against the US dollar and the GDP deflator of all the economies during the period 1973 to 2015 from the World Development Indicators (WDI) published by the World Bank. In some cases, we collected data from the International Financial Statistics (IFS) database published by the IMF when data were not available in the WDI. ${ }^{2}$ In this study, we used unbalanced panel data, that is, the sample period was not identical. The starting periods of Cambodia, Lao PDR, and Vietnam are 1988, 1982, and 1985, respectively. Therefore, we used the Pesaran (2007) test for panel unit root test and the Westerlund (2007) test for the panel cointegration test, which allowed unbalanced panel data.

Although the CPI is widely considered for the PPP theory, in this paper, we used the GDP deflator. The reason for this choice was the unavailability of the CPI for a longer period of time in some countries.

\section{Methodology}

Panel unit root test

To examine the unit root of the panel data, we incorporate the cross-sectionally augmented panel unit root test (CIPS), which was developed by Pesaran (2007). The CIPS test is the augmented version of the conventional Augmented Dickey-Fuller (ADF) regression model with the lagged cross-sectional average and its first difference to obtain the cross-sectionally augmented Dickey-Fuller (CADF) test:

$$
\Delta y_{i, t}=\alpha_{i}+\rho_{i}^{*} y_{i, t-1}+d_{0} \bar{y}_{t-1}+d_{1} \Delta \bar{y}_{t}+\varepsilon_{i, t}
$$

where $\bar{y}_{t}$ is the mean at time $t$ of all $N$ observations. If a serial correlation present in $\varepsilon_{i}$, of (3.1), then (3.1) must be augmented in the following way: 


$$
\Delta y_{i, t}=\alpha_{i}+\rho_{i}^{*} y_{i, t-1}+d_{0} \bar{y}_{t-1}+\sum_{j=0}^{p} d_{j+1} \bar{y}_{t-j}+\sum_{k=1}^{p} c_{k} \Delta \bar{y}_{i, t-k}+\varepsilon_{i, t}
$$

By estimating the CADF regression for each cross-section, $t$-statistics are obtained and subsequently, the CIPS statistic can be found from the mean value of the $t$-statistics:

$$
C I P S=\frac{1}{N} \sum_{i=1}^{N} C A D F_{i}
$$

The CIPS test provides reliable results in the presence of cross-sectional dependence, while the first-generation tests generally disregard the presence of such dependence.

\section{Panel cointegration}

Test 1: To determine the long-run relationship between the panel series, we considered the Westerlund (2007) tests in the paper.

The Westerlund (2007) tests are relatively recently developed error-correction-based panel cointegration tests, comprising four new panel cointegration tests. It is based on structural, rather than residual, dynamics. The tests allow for various forms of heterogeneity and accommodate the $p$-values which are robust against cross-sectional dependences through bootstrapping. The two tests are designed to test the alternative hypothesis that the whole panel is cointegrated, while the other two tests aim to test the alternative hypothesis that at least one cross-section is cointegrated.

The error-correction tests assume the following data-generating process:

$$
\begin{aligned}
\Delta d \ln S_{i t}= & \delta_{i}^{\prime} D_{t}+\alpha_{i}\left[\text { dlnthe } S_{i, t-1}-\beta_{i}^{\prime} d \ln \left(\frac{P_{t-1}^{A_{i}}}{P_{t-1}^{U S}}\right)\right]+\sum_{j=1}^{p_{i}} \alpha_{i j} \Delta d \ln S_{i, t-j} \\
& +\sum_{j=-q_{i}}^{p_{i}} \gamma_{i j} \Delta d \ln \left(\frac{P_{t-j}^{A_{i}}}{P_{t-j}^{U S}}\right)+e_{i t}
\end{aligned}
$$

where $t$ and $i$ represent the time-series and cross-sectional units respectively, while $D_{t}$ contains the deterministic components. Equation (2.4) can be restated in case of any dependence across $i$ by bootstrapping:

$$
\begin{aligned}
\Delta d \ln S_{i t}= & \delta_{i}^{\prime} D_{t}+\alpha_{i} d \ln S_{i, t-1}+\lambda_{i}^{\prime} d \ln \left(\frac{P_{t-1}^{A_{i}}}{P_{t-1}^{U S}}\right)+\sum_{j=1}^{p_{i}} \alpha_{i j} \Delta d \ln S_{i, t-j} \\
& +\sum_{j=-q_{i}}^{p_{i}} \gamma_{i j} \Delta d \ln \left(\frac{P_{\mathrm{t}-j}^{A_{i}}}{P_{t-j}^{U S}}\right)+e_{i t}
\end{aligned}
$$

If $\alpha_{i}<0$, then there is error correction, which implies that $d \ln S_{i, t}$ and $d \ln \left(\frac{P_{t}^{A_{i}}}{P_{t}^{L S}}\right)$ are cointegrated. If $\alpha_{i}=0$, then there is no error correction and, thus, no-cointegration. However, the alternative hypothesis depends on the assumption of the homogeneity of $\alpha$. In the case of group-mean test, the alternative hypothesis is $H_{1}^{G}: \alpha_{i}<0$ for at least one $i$. Unlike the group-mean tests, the alternative hypothesis, in the case of the panel tests, is stated as $H_{1}^{P}: \alpha_{i}<0$ for all $i$. Westerlund (2007) and Persyn and Westerlund (2008) proposed four panel cointegration test statistics in this regard: $G_{\tau}, G_{\alpha}, P_{\tau}$ and $P_{\alpha}$. The two panel cointegration test statistics $G_{T}, P_{\tau}$ are developed considering the 
Table 1 Panel Unit Root Test Results Using Pesaran (2007)

\begin{tabular}{lll}
\hline Variables & Level & \\
\cline { 2 - 3 } & Without Trend & With Trend \\
\hline$d \ln S_{i t}$ & $-5.133^{\mathrm{a}}$ & $-4.107^{\mathrm{a}}$ \\
$d \ln \left(\frac{p_{t}^{A_{i}}}{p_{t}^{W_{t}}}\right)$ & $-4.767^{\mathrm{a}}$ & $-3.691^{\mathrm{a}}$
\end{tabular}

Note: ${ }^{a}$ indicates $1 \%$ significance level

conventional standard errors. On the other hand, the other two statistics, $G_{\alpha}$ and $P_{\alpha}$, used Newey and West's (1994) standard errors to explicitly consider heteroscedasticity and serial correlation problems.

The group-mean test can be estimated in the following manner:

$$
G_{\tau}=\frac{1}{N} \sum_{i=1}^{N} \frac{\hat{\alpha}_{i}}{S E\left(\hat{\alpha}_{i}\right)}
$$

and

$$
G_{\alpha}=\frac{1}{N} \sum_{i=1}^{N} \frac{T \hat{\alpha}_{i}}{\hat{\alpha}_{i}(1)}
$$

where $\operatorname{SE}\left(\hat{\alpha}_{i}\right)$ is the standard error of $\hat{\alpha}_{i}$. Conversely, the panel statistics can be estimated as follows:

$$
P_{\tau}=\frac{\hat{\alpha}}{S E(\hat{\alpha})}
$$

and

$$
\mathrm{P}_{\alpha}=T \hat{\alpha}
$$

\section{Empirical results}

Table 1 presents the results of the panel unit root tests. Both tests consider the constant as well as the constant and trend and provide evidence that the nominal exchange rate and the price level ratio do not contain the unit root problem in their level. That is, these two variables are stationary in their level difference and hence, the series are integrated of order zero (0). These results provide the basis for the test of the long-run relationship between the two variables.

To obtain an unambiguous result, we incorporated the Westerlund (2007) tests for the panel cointegration analysis. This is also known as the second-generation test.

Table 2 Panel Asymptotic Cointegration Test

\begin{tabular}{llll}
\hline Statistic & Value & Z-value & $P$-value \\
\hline$G_{T}$ & -5.177 & -11.107 & 0.000 \\
$G_{a}$ & -33.556 & -10.296 & 0.000 \\
$P_{T}$ & -16.211 & -11.100 & 0.000 \\
$P_{a}$ & -45.353 & -19.270 & 0.000 \\
\hline
\end{tabular}

Note: All tests are implemented with the constant and trend in the test regression. For semi-parametric corrections, Newey and West (1987) developed the Bartlett kernel is employed. The lags and leads in the error-correction test are chosen according to the Akaike information criterion developed by Akaike (1973). All other bandwidth and lag orders are set according to the rule $4(T / 100) 2 / 9 \approx 1$. The null hypothesis of the cointegration tests are no-cointegration. The $p$-values are for a one-sided test based on the normal distribution 
Table 3 Panel Bootstrap Cointegration Test

\begin{tabular}{lllll}
\hline Statistic & Value & Z-value & $P$-value & Bootstrapped $p$-value \\
\hline$G_{T}$ & -4.464 & -8.164 & 0.0000 & 0.003 \\
$G_{a}$ & -26.554 & -6.762 & 0.0000 & 0.003 \\
$P_{T}$ & -14.398 & -8.825 & 0.0000 & 0.013 \\
$P_{a}$ & -34.35 & -13.109 & 0.0000 & 0.003 \\
\hline
\end{tabular}

Note: All tests are implemented with the constant and trend in the test regression. For semi-parametric corrections, Newey and West (1987) developed the Bartlett kernel is employed. The lags and leads in the error-correction test are chosen according to the Akaike information criterion developed by Akaike (1973). All other bandwidth and lag orders are set according to the rule $4(T / 100) 2 / 9 \approx 1$. The null hypothesis of the cointegration tests are no-cointegration. The $p$-values are for a one-sided test based on the normal distribution. The number of bootstraps to obtain bootstrap $p$-values, which are robust against cross-sectional dependences, is set to 400

The calculated values of the error-correction statistics of the Westerlund (2007) tests are presented along with asymptotic $p$-values in Table 2 . The panel tests have the maximum power since they are based on the pooled least squares estimator of $\alpha$. Pooling is efficient under the homogenous alternative consideration. Among the panel tests, we find that $P \alpha$ has the highest power. Among the group-mean tests, the results suggest that $G \alpha$ has the highest power. According to Table 2, we can reject the null hypothesis of no-cointegration between the relative change in the exchange rate and the price levels at the $1 \%$ level for all of the residual-based tests. While using the asymptotic $p$-values, we see that all four tests reject the null overwhelmingly, even at the most conservative $1 \%$ level, which we regard as strong evidence in favor of the relative PPP theory.

The estimated error-correction statistics of the Westerlund (2007) tests are presented along with bootstrapped $p$-values in Table 3. According to the bootstrapped $p$-values, we end up with one rejection for $P$ at the $5 \%$ significance level. The other error-correction statistics $G_{\mathrm{\tau}}, G_{\alpha}$ and $P_{\alpha}$ are statistically significant at the $1 \%$ level. The findings of the asymptotic $p$-values coincide with the bootstrapped $p$-values.

Finally, most of the ASEAN countries are of equal economic strength. However, Indonesia's economy is significantly larger than the rest. Brunei's economy is rather small. Hence, to check the robustness of the earlier findings presented in Tables 2 and 3 , the Westerlund (2007) panel cointegration tests can be conducted again after excluding these two countries. The results of the panel asymptotic cointegration test and the panel bootstrap cointegration test are illustrated in Tables 4 and 5 , respectively,

According to Table 4, three statistics out of four, namely, $G_{t}, G_{\alpha}$, and $P_{\alpha}$, are statistically significant at the $1 \%$ level. Therefore, we can reject the null hypothesis of

Table 4 Panel Asymptotic Cointegration Test (Excluding Indonesia And Brunei)

\begin{tabular}{llll}
\hline Statistic & Value & Z-value & $P$-value \\
\hline$G_{T}$ & -5.305 & -10.386 & 0.000 \\
$G_{a}$ & -20.385 & -3.609 & 0.000 \\
$P_{\tau}$ & -1.712 & 4.967 & 1.000 \\
$P_{a}$ & -14.504 & -2.628 & 0.004 \\
\hline
\end{tabular}

Note: All tests are implemented with the constant and trend in the test regression. For semi-parametric corrections, Newey and West (1987) developed the Bartlett kernel is employed. The lags and leads in the error-correction test are chosen according to the Akaike information criterion developed by Akaike (1973). All other bandwidth and lag orders are set according to the rule $4(T / 100) 2 / 9 \approx 1$. The null hypothesis of the cointegration tests are no-cointegration. The $p$-values are for a one-sided test based on the normal distribution 
Table 5 Panel Bootstrap Cointegration Test (Excluding Indonesia And Brunei)

\begin{tabular}{lllll}
\hline Statistic & Value & Z-value & $P$-value & Bootstrapped $p$-value \\
\hline$G_{T}$ & -4.394 & -7.056 & 0.000 & 0.005 \\
$G_{a}$ & -20.545 & -3.549 & 0.000 & 0.005 \\
$P_{T}$ & -11.517 & -6.337 & 0.000 & 0.013 \\
$P_{a}$ & -24.087 & -6.991 & 0.000 & 0.008 \\
\hline
\end{tabular}

Note: All tests are implemented with the constant and trend in the test regression. For semi-parametric corrections, Newey and West (1987) developed the Bartlett kernel is employed. The lags and leads in the error-correction test are chosen according to the Akaike information criterion developed by Akaike (1973). All other bandwidth and lag orders are set according to the rule $4(T / 100) 2 / 9 \approx 1$. The null hypothesis of the cointegration tests are no-cointegration. The $p$-values are for a one-sided test based on the normal distribution. The number of bootstraps to obtain bootstrap $p$-values, which are robust against cross-sectional dependences, is set to 400

no-cointegration between the relative change in the exchange rate and the price levels at the $1 \%$ level. This result also supports the validity of the PPP hypothesis.

According to the bootstrapped $p$-values in Table 5, all the error-correction statistics are statistically significant at least at the $5 \%$ significance level. After checking the robustness of the prior results, we can assert that the PPP theory is valid in the ten ASEAN member countries.

These results are also consistent with $\mathrm{Ha}$ (2018). Using panel data methods and considering structural breaks, Ha (2018) found that the PPP hypothesis is valid in nine Southeast Asian countries, namely Vietnam, Laos, Cambodia, Thailand, Myanmar, Malaysia, Singapore, Indonesia, and the Philippines between July 1997 and August 2008. Soon et al. (2017), using second-generation panel unit root tests, also found evidence for the PPP hypothesis in Southeast Asian countries. Therefore, the findings of this study are consistent with the prior studies on the PPP theory in ASEAN countries where structural breaks are incorporated in the panel data methods.

\section{Conclusion}

This paper has examined the relevance of the relative PPP theory during the period 1973 to 2015 for the ten ASEAN member countries as against the US by analyzing panel data. According to Pesaran's (2007) CIPS test, the relative change in the exchange rate and the relative change in the price level ratio are stationary. That is, they are integrated of order zero (0). This provides some basis for the panel cointegration test. The results obtained from the four error-correction-based Westerlund (2007) panel cointegration tests overwhelmingly support the relative PPP hypothesis. To check the robustness of the study, we estimate the cointegration test excluding Indonesia and Brunei and find support for our prior results. According to this empirical analysis, both asymptotic and bootstrapped $p$-values provide evidence of the validity of the PPP theory. However, the PPP hypothesis can be investigated further through employing monthly or quarterly data. Structural breaks, Asian financial crisis can be incorporated in analyzing the PPP theory.

The results of this paper imply that the relative change in the exchange rate and the relative change in the price level ratio are cointegrated. Therefore, the monetary authority can undertake a self-regulating monetary policy to fine tune their economy. The monetary authority would have sovereignty over their monetary policy in an open economy. They would also be able to control the fluctuations in exchange rates. 


\section{Endnotes}

${ }^{1}$ For examples, Frenkel (1978), Baharumshah and Ariff (1997), Taylor (2006).

${ }^{2}$ For instance, some missing data of Brunei Darussalam were collected from the IFS.

\section{Acknowledgments}

The authors are grateful to two anonymous referees and the editor of this journal for their constructive and helpful comments.

\section{Funding}

We do not receive any financial assistance from any agency. All the cost associated with preparing article bear by authors solely.

\section{Availability of data and materials}

Upon request in the future, we, hereby, confirming that all the pertinent information will be disclosed for further use.

\section{Authors' contributions}

The concept and design of this article come from Professor MAH and thereafter data collection, data analysis, empirical study, review of conceptual development and drafting done by SMWM. Considering the effort by authors in the article, the ratio of contribution equally likely. Both authors read and approved the final manuscript.

\section{Competing interests}

The authors declare that they have no competing interests.

\section{Publisher's Note}

Springer Nature remains neutral with regard to jurisdictional claims in published maps and institutional affiliations.

\section{Author details}

'Department of Economics, Noakhali Science and Technology University, Noakhali 3814, Bangladesh. ${ }^{2}$ Department of Economics, Jahangirnagar University, Savar, Dhaka 1342, Bangladesh.

Received: 26 October 2017 Accepted: 15 October 2018

Published online: 22 October 2018

\section{References}

Aggarwal R, Montanes A, Ponz M (2000) Evidence of long-run power parity: analysis of real Asian exchange rates in terms of the Japanese yen. Jpn World Econ 12:351-361.

Ahn C, Kim HB, Chang D (2006) Is East Asia fit for an optimum currency area? An assessment of the economic feasibility of a higher degree of monetary cooperation in East Asia. Dev Econ 44(3):288-305.

Akaike H (1973) Information theory and an extension of the maximum likelihood principle. In: Petrov BN, Csaki F (eds) Second International Symposium on Information Theory. Akailseoniai-Kiudo, Budapest, pp 267-281.

Anker P (1999) Pitfalls in panel tests of purchasing power parity. Rev World Econ 135(3):437-453.

Baharumshah AZ, Ariff M (1997) Purchasing power parity in South East Asia countries economics: a Cointegration approach. Asian Econ J 11:141-153.

Baltagi BH, Kao C (2000) Nonstationary panels, cointegration in panels and dynamic panels: a survey. In: Baltagi BH (ed) Nonstationary panels, panel cointegration, and dynamic panels. Advances in Econometrics, vol 15, pp 7-52.

Banerjee A (1999) Panel data unit roots and cointegration: an overview. Oxf Bull Econ Stat 61(S1):607-629.

Breitung J, Candelon B (2005) Purchasing power parity during currency crises: a panel unit root test under structural breaks. Rev World Econ 141(1):124-141.

Chang T, Lee CH, Liu WC (2012) Nonlinear adjustment to purchasing power parity for ASEAN countries. Jpn World Econ 24(4):325-331.

Chen M, Hu X (2018) Linkage between consumer price index and purchasing power parity: theoretic and empirical study. J Int Trade Econ Dev. https://doi.org/10.1080/09638199.2018.1430164.

Choudhry T (2005) Asian currency crisis and the generalized PPP: evidence from the Far East. Asian Econ J 19(2):137-157. Engel C (2000) Long-run PPP may not hold after all. J Int Econ 57(2):243-273.

Fleissig AR, Strauss J (2000) Panel unit root tests of purchasing power parity for Price indices. J Int Money Financ 19(4):489-506.

Frenkel JA (1978) Purchasing power parity doctrinal perspective and evidence from the 1920s. J Int Econ 8(2):169-191.

Froot KA, Rogoff K (1995) Perspectives on PPP and long-run real exchange rates. In: Grossman G, Rogoff K (eds) Handbook of international economics, vol 3, North Holland, Elsevier Science, pp 1647-1688.

Ha MATT (2018) Testing the evidence of purchasing power parity for Southeast Asia countries. In: Anh L, Dong L, Kreinovich V, Thach N (eds) Econometrics for financial applications. ECONVN 2018. Studies in computational intelligence, vol 760. Springer, Cham

Kapetanios G, Shin Y, Snell A (2003) Testing for a unit root in the nonlinear STAR framework. J Econ 112:359-379.

Kim BH, Kim HG, Oh KY (2009) Purchasing power parity in southeast Asian currencies: a time-varying coefficients approach. Econ Model 26(1):96-109.

Liew VK, Baharumshah AZ, Chong TT (2004) Are Asian real exchange rates stationary? Econ Lett 83:313-316.

Ma W, Li H, Park SY (2017) Empirical conditional quantile test for purchasing power parity: evidence from east Asian countries. Int Rev Econ Financ 49(May):211-222. 
Murad SMW (2016) Is the exchange rate of Bangladesh mean reverting? A panel unit root approach. Asian Econ Financ Rev 6(2):100-108.

Newey WK, West KD (1987) A simple, positive semi-definite, Heteroskedasticity and autocorrelation consistent covariance matrix. Econometrica 55(3):703-708.

Newey WK, West KD (1994) Automatic lag selection in covariance matrix estimation. Rev Econ Stud 61:631-653.

O'Connell PG (1998) The overvaluation of purchasing power parity. J Int Econ 44:1-9.

Ogawa E, Kawasaki K (2006) Adopting a common currency basket arrangement into the ASEAN plus three. In: RIETI Discussion Paper Series 06-E-028, June.

Pedroni P (2000) Fully modified OLS for heterogeneous cointegrated panels. In: Baltagi BH (ed) Nonstationary panels, panel cointegration, and dynamic panels, advances in econometrics, vol 15, pp 93-130.

Pedroni P (2001) Purchasing power parity tests in cointegrated panels. Rev Econ Stat 83:727-731.

Persyn D, Westerlund J (2008) Error-correction-based cointegration tests for panel data. Stata J 8:232-241.

Pesaran MH (2007) A simple panel unit root test in the presence of cross section dependence. J Appl Econ 22(2):265-312.

Rogoff K (1996) The purchasing power parity puzzle. J Econ Lit 34:647-668.

Sarno L, Taylor, M (2002) IMF Econ Rev 49: 65. https://doi.org/10.2307/3872492.

Soon SV, Baharumshah AZ, Shariff NSM, Ibrahim S (2017) Currency crises and purchasing power parity in the Asian countries: evidence based on second-generation panel unit-root tests. Malays J Econ Stud 54(1):41-59.

Taylor A, Taylor M (2004) The purchasing power parity debate. J Econ Perspect 18:135-158.

Taylor MP (2006) Real exchange rates and purchasing power parity: mean-reversion in. Economics 16:1-17.

Taylor MP, Sarno L (1998) The behavior of real exchange rates during the post- Bretton woods period. J Int Econ 46(2):281-312.

Westerlund I (2007) Testing for error correction in panel data. Oxf Bull Econ Stat 69:709-748.

Wu JL, Chen SL (1999) Are real exchange rates stationary based on panel unit- root tests? Evidence from Pacific Basin countries. Int J Financ Econ 4:243-252.

Wu JL, Tsai L, Chen SL (2004) Are real exchange rates non-stationary? The Pacific Basin perspective. J Asian Econ 15(2):425438.

Wu JL, Wu S (2001) Is purchasing power parity overvalued? J Money Credit Bank 33:804-812.

Zurbruegg R, Allsopp L (2004) Purchasing power parity and the impact of the east Asian currency crisis. J Asian Econ 15:739-758.

\section{Submit your manuscript to a SpringerOpen ${ }^{\circ}$ journal and benefit from:}

- Convenient online submission

- Rigorous peer review

- Open access: articles freely available online

High visibility within the field

- Retaining the copyright to your article

Submit your next manuscript at $\boldsymbol{\nabla}$ springeropen.com 